JOURNAL OF ISLAMIC EDUCATION

Vol. 6 No. I May 202 I

P-ISSN 2503-5363; E-ISSN 2528-0465

http://www.ejournal.stitmuhbangil.ac.id/index.php/jie

\title{
Peran Syeikh dalam Pembentukan Karakter Generasi Ranah Minangkabau Sumatera Barat di Lembaga Pendidikan Surau
}

\author{
Yusutria \\ (Universitas Ahmad Dahlan, Jl. Kapas No.9, Daerah Istimewa Yogyakarta) \\ yusutria@pai.uad.ac.id
}

\begin{tabular}{|c|c|}
\hline Informasi Artikel & Abstract \\
\hline $\begin{array}{l}\text { Received: } \\
19 \text { February } 2021\end{array}$ & $\begin{array}{l}\text { A good nation is a nation that has a character } \\
\text { that is manifested in thoughts, feelings, attitudes, } \\
\text { behaviors, and confiaurations that are based on }\end{array}$ \\
\hline Accepted: & religious, legal, customary, religious, and cultural \\
\hline 15 April 2021 & $\begin{array}{l}\text { values. Not a drug addict, which will damage the } \\
\text { morals of religion and culture. To realize a }\end{array}$ \\
\hline Published: & generation of character, the role of the Syeikh is \\
\hline 10 May 2021 & $\begin{array}{l}\text { needed in the formation of the character of the } \\
\text { generation of the Minangkabau realm of West }\end{array}$ \\
\hline $\begin{array}{l}\text { Keywords: } \\
\text { Character, Minangkabau }\end{array}$ & $\begin{array}{l}\text { Sumatra in the Surau educational institution. The } \\
\text { purpose of the study is to study the character }\end{array}$ \\
\hline realm generation, Surau & $\begin{array}{l}\text { shape of students, the role of the Syeikh in } \\
\text { character formation. As a result of research, } \\
\text { research is conducted by collecting data through } \\
\text { interviews, observation, documentation. While the } \\
\text { forms of character instilled religious values, } \\
\text { discipline, honesty, independence is hard work full } \\
\text { of creativity, curiosity with the full sense of } \\
\text { responsibility. Sheikh managed to become a good } \\
\text { character, instilling good and responsible habits, } \\
\text { encouraging and innovating. }\end{array}$ \\
\hline
\end{tabular}

\section{Pendahuluan}

Bangsa yang baik adalah bangsa memiliki generasi yang baik, baik dari segi agama, etika, estetika, moral dan akhlaq. Generasi yang baik akan memiliki karakter yang membentuk nilai-nilai kepribadian yang behubungan dengan sesama manusia, hubungan manusia dengan Tuhannya, dirinya sendiri, lingkungan dan dalam berbangsa serta bernegara, yang terwujud dalam 
pikiran, perasaan, sikap, perbuatan dan berkataan yang berdasarkan pada nilainilai agama, hukum, adat, tatakarama dan budaya yang ada di daerah. Pembentukan generasi yang berkarakter tidak hanya di lingkungan sekolah, tapi juga di lingkungan rumah dan masyarakat (Anwar, 2021).

Generasi muda adalah pemimpin untuk akan datang. Oleh karena itu untuk membangun generasi yang baik dibutuhkan keseriusan dan kesungguhan dalam membentuk karakter manusia Indonesia yang akan menjadi manusia seutuhnya dalam upaya perbaikan moral bangsa menghadapi era globalisasi (Al-Nashr, 2010). Karena, generasi yang memiliki dekadensi moral yang terjadi pada generasi Indonesia pada saat sekarang ini sangat menyedihkan, hal ini bisa dilihat banyaknya generasi yang menjadi pecandu narkoba, kurangnya rasa hormat pada guru (Zubaedi, 2011), dan mengadopsi budaya yang akan merusak moral keagamaan dan budaya yang ada (Suradarma, 2018), melakukan tindakan kriminal, bebas seks dan yang lainnya (Izzah, 2018). Jika generasi seperti ini yang banyak, bagaimana akan menjadi pemimpin untuk akan datang dan bisa membawa negara ini ke arah yang baik. Hal tersebut terjadi karena kurangnya sistem pendidikan yang lebih menekankan pengembangan intelektual dari pada pembentukan karakter dan kurangnya dukungan lingkungan dan masyarakat dalam mendukung pengembangan karakter tersebut (Saleh, 2017). Untuk terwujudnya pendidikan yang berkarakter diperlukan keterlibatan dari berbagai pihak, baik pihak pemerintah, akademik, masyarakat dan lingkungan keluarga (Yusutria, 2018).

Sumatera Barat pada zaman dahulunya banyak melahirkan para ulama, orang-orang hebat secara intelelektual, dan berkarakter yang terpandang di kancah nasional dan international diantaranya, Buya Hamka, M. Yamin, Bung Hatta, M. Natsir, Rahma El-yunusiah. Semua ulama tersebut pernah mengenyam pendidikan di lembaga pendidikan Surau. Surau sebagai lembaga pendidikan Islam yang pernah ada di Minangkabau Sumatera Barat, merupakan lembaga yang punya andil dalam mendidik generasi minang, menanamkan 
nilai-nilai keagamaan, estetika, moral dan etika, serta belajar al-Qur'an dan tempat pelaksanaan ibadah. Intinya lembaga pendidikan Surau berfungsi secara sosiokultural, individual, agamis (Khadimullah, 2007). Sumatera Barat merupakan daerah yang terkenal dengan filosof adat yang dipegang teguhnya, khususya masyarakat Minangkabau yang ada di Sumatera Barat, yaitu "Adat Basandi Syarak, Syarak Basandi Kitabullah" (ABS-SBK), yaitu adat yang berdasarkan pada hukum, hukum berdasarkan kepada Kitab Allah (Susanti, 2014).

Membangun generasi yang berkarakter di Sumatera Barat yang akan mendukung fungsi pendidikan Nasional yang tertuang dalam Undang-undang RI No 20 Tahun 2003 tentang Sistem Pendidikan Nasional pasal 3. (UU RI No. 20 tahun 2003 Pasal 3), dan diperlukannya juga Peraturan Daerah/ Perda 03 tahun 2007 tentang pendidikan bernuansa surau yang diimplementasikan dalam pendidikan formal yang ada disluruh penjuru daerah Sumatera Barat. Dengan adanya peraturan tersebut akan bisa mendorong masyarakat untuk menjalankan tata kehidupan sosial yang bernuansa adat dan agama dan mampu diimplentasikan dalam berbagai kehidupan sosial masyarakat (Darwianis, 2017).

Lembaga pendidikan Surau yang ada di Sumatera Barat banyak sekali diantara Surau Syaikh Burhanuddin, Surau Lubuk Bauk, Surau Tuo, Surau Sicincin, Surau Syaikh Mato Aie yang ada di Nagari VII Lingkungan Padang Pariaman, yang mana surau-surau tersebut berperan penting dan memiliki kontribusi yang besar dalam membentuk generasi yang berkarakter. Sehingga peneliti ingin membahas tentang peran syeikh dalam pembentukan karakter generasi ranah Minangkabau Sumatera Barat di lembaga pendidikan surau.

Berdasarkan kajian teori berikut pengertian surau sebagai pusat kebudayaan dan ilmu pengetahuan umum dan agama serta sebagai basis gerakan politik, yang mengembangkan pendidikan yang berazazkan agama Islam, dalam aspek pemahaman dan penanaman nilai-nilai moral. Surau 
sebagai lembaga pendidikan Islam tradisional yang memiliki peran sebagai lembaga pendidikan agama, lembaga pendidikan adat dan budaya atau kearifan lokal dan menjadi pusat kegiatan aktifitas masyarakat (Natsir, 2012). Lembaga pendidikan Surau merupakan perwujudan akan nilai-nilai kearifan lokal yang mengakar dalam kehidupan masyarakat Minangkabau yang inheren dan lembaga religius (Mursal, 2018). Pengembangan nilai-nilai moral agama dan budaya di Minangkabau ada dilembaga pendidikan Surau.

Sehingga surau merupakan suatu lembaga pendidikan yang ada di Sumatera Barat sebagai wadah bagi pendidikan dan pembentukan karakter generasi Minangkabau Sumatera Barat, dalam lembaga pendidikan surau tersebut dikembangan kecerdasan emosional, spritual, intelektual, sosial dalam masyarakat yang berdasarkan pada falsafah "Adat Basandi Syarak, Syarak basandi Kitabullah"

Pendidikan karakter menjadi bagian penting baik dalam dunia pendidikan dalam bersikap, tindakan, corak berfikir dalam bermasyarakat, berbangsa dan bernegara. maupun dalam penentu kesuksesan kehidupan seseorang, maka pendidikan karakter sangat diperlukan. Sehingga pendidikan yang ada tidak diminta hanya cerdas secara intelektual, tapi juga harus cerdas secara emosional dan spritual, bukan hanya hard skill tapi juga harus soft skill. Pendidikan karakter dipahami sebagai metode pengajaran kebiasaan cara berpikir, berperilaku dan bekerjasama sebagai anggota keluarga, masyarakat dan bernegara, serta mampu membuat keputusan yang dapat dipertanggungjawabkan (Ikhwan, 2017).

Pembentukan karakter generasi dalam masyarakat Minangkabau Sumatera Barat merupakan suatu media pada masa lalu, sebagai tempat berkumpulnya orang siak dalam menimba ilmu yang memiliki tujuan yang sama dan hidup dalam tatanan sosial yang sama sehingga mampu membentuk sebuah budaya dan identitas yang dikenal dalam suatu masyarakat yang berbasiskan nilai adat, keagamaan dan kemasyarakatan (Navis, 1983). Hal 
tersebut sesuai dengan tujuan pendidikan yang mengedepankan pada pendidikan akhlak yang berprilaku jujur, adil, tidak membedakan satu sama lainnya, pekerja keras, dan bertanggungjawab dalam setiap perbuatan (Syafe'i, 2017). Lembaga pendidikan Surau sudah memiliki beberapa aspek sebagai pendukung pendidikan karakter diantaranya aspek akademik yaitu bahasa, aspek keterampilan dalam life skill, aspek religi dalam masalah ubudiyah baik yang berhubungan dengan Allah, sesama manusia, dan lingkungan, kultur.

Pendidikan karakter bersumber dari agama, pancasila, budaya dan tujuan pendidikan nasionalmitu ada 18 nilai; yaitu: 1. Religius, 2. Jujur, 3. Toleransi, 4. Disiplin, 5. Kerja keras, 6. Kreatif, 7. Mandiri, 8.demokratis, 9. Rasa ingin tahu, 10. Semangat kebangsaan, 11. Cinta tanah air, 12. Menghargai prestasi, 13. Bersahabat, 14. Cinta damai, 15. Gemar membaca, 16. Peduli lingkungan, 17. Peduli sosial, 18. Tanggung jawab (Nasrullah, 2019).

Pembentukan kepribadian dan karakter seseorang dibutuhkan suatu pembiasaan dalam melakukan hal-hal yang baik dan terpuji, juga diawali dengan meniru, menghafal dan pembiasaan (Gunaawan, 2014), yang harus ditanamkan dalam diri, Pendidikan karakter juga dimulai melalui kegiatan pembelajaran (Aini, 2018). Karakter sangat besar kontribusinya dalam mewujudkan potensi dan cita-cita seseorang untuk membangun kehidupan yang labih baik ke depan. Ada beberapa aspek yang menjadikan pendidikan karakter diperlukan; 1. Aspek dogmatis, 2. Aspek sosio kultural yang menjadikan hubungan normatif antara budaya, masyarakat dan individu, 3. Aspek historis, 4. Aspek politik, aspek religiusitas, bahwa perbincangan pendidikan karakter tidak bisa dilepaskan dari pendidikan agama (Lickona, 1991).

\section{METODE PENELITIAN}

Penelitian ini merupakan penelitian lapangan (field research) yang bersifat kualitatif (qualitatif research), penelitian yang tidak menekankan pada 
generalisasi, tetapi lebih menekankan pada makna dalam penelitian (Sugiyono, 2010), untuk mendeskripsikan dan menganalisis fenomena, peristiwa, sikap, dan aktivitas sosial yang berkaitan dengan peran lembaga pendidikan surau dalam pembentukan karakter generasi di ranah minangkabau Sumatera Barat.

Adapun metode pengumpulan data menggunakan metode wawancara, observasi, dokumentasi (Widoyoko, 2012). Penganalisis data dilakukan dengan mengelompokan data, menjabarkan, melakukan sintesa, menyusun ke dalam pola, serta memisahkan mana yang penting dan membuat kesimpulan (Salim \& Syahrum, 2012).

\section{TEMUAN DAN PEMBAHASAN}

penelitian tentang kontribusi lembaga pendidikan surau dalam pembentukan karakter generasi di ranah Minangkabau Sumatera Barat.

\section{Bentuk-bentuk karakter peserta didik/faqiah}

Pembentukan dan penanaman karakter generasi di ranah Minangkabau Sumatera Barat kepada peserta didiknya/faqiahnya dengan membudayakan salam dan sapa dalam bermasyarakat baik internal maupun dengan masyarakat luas, menanamkan budaya bersalaman pada syeikh, guru sebelum belajar dan sesudah belajar, membudayakan jalan agak membungkuk di depan syeikh dan guru. Hal tersebut sesuai dengan hasil wawancara yang telah dilakukan dengan guru tuo:

"Pembentukan dan penanaman karakter kepada generasi di ranah Minang ini melalui suritauladan, kebiasaan, memotivasi kepada peserta didik/faqiah seperti membiasakan salam, sapa antara peserta didik/faqiah, serta adanya budaya berjalan agak rendah di depan syeikh, kegigihan dalam menghadapi kehidupan, mengedepankan sikap kejujuran."

Hal tersebut dipertegas oleh syeikh berdasarkan hasil wawancara sebagai berikut:

"Bentuk-bentuk nilai-nilai karakter tersebut teraplikasi dalam kehidupan sehari-hari dengan penuh nilai-nilai agamis yang religius penuh kejujuran 
dalam berbuat, dan disiplin dalam setiap melaksanakan kegiatan yang ada, hal tersebut bisa dilhat dari semangatnya yang penuh kreatif dan mandiri serta penuh dengan rasa penasaran untuk mengetahui yang belum diketahuinya tentunya diiringi dengan penuh rasa tanggung jawab dalam setiap perkataan dan perbuatan yang telah dilakukannya baik sebagai peserta didik maupun sebagai berbangsa dan bernegara."

Dengan demikian, bentuk-bentuk karakter yang ditanamkan adalah nilainilai agama yang kuat dalam menuntut ilmu agama dan disiplin dalam menuntut ilmu dan termotivasi dalam rasa ingin tahu dalam mengetahui ilmu yang belum diketahuinya serta adaya rasa peduli terhadap teman sejawat dan masyarakat (Ikhwan, 2020). Sebagai peserta didik juga ada dalam dirinya rasa tanggung jawab yang besar dalam berbangsa dan bermasyarakat.

\section{Stategi syeikh dalam pembentukan karakter generasi di ranah Minangkabau Sumatera Barat}

Strategi yang digunakan syeikh dengan memadukan karakter dalam kegiatan sehari-hari seperti pemberian keteladanan, pendampingan dan pengawasan dari guru tuo yang ada melalui setiap kegiatan yang ada. Hal tersebut sesuai dengan hasil wawancara dengan guru sebagai berikut:

"Adapun strategi yang digunakan oleh syeikh dalam pembentukan karakter generasi di ranah Minangkabau Sumatera Barat di dukung dengan motivasi, inspirasi, ketauladanan dan pembiasaan berdasarkan dengan berbagai macam kegiatan yang ada di lingkungan Surau."

Berdasarkan dengan observasi yang dilakukan bahwa peran Syeikh dalam pembentukan karakter generasi ranah Minangkabau Sumatera Barat di lembaga pendidikan Surau sudah baik dalam realita kehidupan yang dijalani oleh peserta didik/faqiah yang ada di Surau. Sebagi insan yang religius, penuh dengan kejujuran, dengan kedisiplian yang baik, adanya semangat dalam bekerja keras penuh dengan ide dan gagasan yang kreatif, mandiri dan penuh dengan rasa ingin tahu dan rasa tanggung jawab terhadap berbangsa dan bernegara yang berdasarkan pada agama. 
Hal tersebut sesuai dengan UU No. 20 Tahun 2003 tentang sistem Pendidikan Nasional pada fungsi lembaga pendidikan dan tujuan pendidikan nasional (UU SISDIKNAS No. 20 Tahun 2003).

\section{UCAPAN TERIMA KASIH}

Ucapan terima kasih kepada seluruh pihak yang telah membantu peneliti untuk menyelesaikan penelitian yang berkaitan dengan penelitian ini, khususnya pengelola lembaga pendidikan surau Syeikh Mato Aie.

\section{KESIMPULAN}

Lembaga pendidikan Surau memiliki tujuan pendidikan karakter yangdidasarkan kepada al-qur'an dan hadits, haltersebut tercermin dalam realita kehidupan yang tercermin pada nilai-nilai religius, jujur, toleransi, disiplin, bekerja keras, demokratis, memiliki tanggungjawab yang besar dalam beragama, berbangsa dan bernegara. Pembentukan karakter tersebut dapat ditanamkan melalui pembiasaan, uswatun hasanah/suritauladan, amal mar'ruf nahi mungkar, hukuman dan balasan yang seimbang. Sebagai seorang guru juga menjadi sebagai inspirator, motivator, keteladanan, dinamisator, evaluator terhadap nilai-nilai pendidikan yang telah ditransfer kepada peserta didiknya.

Peneliti yang menyarankan kepada pihak sekolah, baik pendidik dan tenaga pendidikan serta masyarakat sekitar dan penuh dukungan dengan orang tua hendaknya menjadi suritauladan, panutan, pemberi inspirasi terhadap generasi muda agar memiliki karakter yang baik.

\section{BIBLIOGRAFI}

[1] Aini, Z. (2018). Implementasi pendidikan karakter dalam pembelajaran bahasa arab di ma sunan ampel baujeng. Journal of Islamic Education, $3(1), 35-46$.

[2] Al-Nashr, M. S. (2010). Pendidikan Karakter Berbasis Kearifan Lokal: Telaah Pemikiran KH. Abdurrahman Wahid. Semarang: Skripsi IAIN 
Walisongo Semarang.

[3] Anwar, S. (2021). Internalisasi Nilai Pendidikan Akhlak dalam Surat AlHujurat Tafsir fi ZIlalil Qur' an. JIE: Journal of Is/amic Edication, 6(1), 112.

[4] Darwianis. (2017). Tindaklanjut Kebijakan Kembali ke Nagari dan ke Surau Serta Dampaknya Terhadap Kehidupan Sosial Adat Kegamaan Masyarakat. Jurnal PPKn \& Hukum, 12(2), 97.

[5] Gunaawan, H. (2014). Pendidikan Karakter: Konsep dan Implementasi. Bandung: Alfabeta.

[6] Ikhwan, A. (2017). Metode Simulasi Pembelajaran dalam Perspektif Islam. Istawa: Jurnal Pendidikan Islam, 2(2), 1-34. https://doi.org/10.24269/ijpi.v2i2.623

[7] Ikhwan, A. (2020). Development of Educational Resources in Junior High Schools to Obtain Quality. Cendekia: Jurnal Kependidikan Dan Kemasyarakatan, 18(1), 1-16. https://doi.org/https://doi.org/10.21154/cendekia.v1i1.1897

[8] Izzah, I. (2018). Peran Pendidikan Agama Islam Dalam membentuk Masyarakat Madani. Jurnal Pedagogik, 5(1), 51.

[9] Khadimullah, T. K. (2007). Menuju Tegaknya Syariat Islam di Minangkabau: Peranan Ulama Sufi dalam Pembaharuan Adat. Bandung: Penerbit Marja.

[10] Lickona, T. (1991). Education for Charahter. New York: Batam Book.

[11] Mursal, I. F. (2018). Surau dan Sekolah; Dualisme Pendidikan di Bukittinggi 1901-1942. Titian: Jurnal Ilmu Humaniora, 2(1), 100.

[12] Nasrullah, N. (2019). Upaya Guru Pendidikan Agama Islam Dalam Membentuk Karakter Siswa (Studi Kasus Di Sma Negeri 1 Kota Bima). JIE (Journal of Islamic Education), 3(2), 163.

[13] Natsir, M. (2012). Peranan Surau Sebagai Lembaga Pendidikan Islam Tradisional di Padang Pariaman Sumatera Barat (Surau Syaikh Burhanuddin). Pedagogi: Jurnal Ilmu Pendidikan, 12(2), 39.

[14] Navis, A. A. (1983). Dialektika Minangkabau dalam Kemelut Sosial dan Politik. Padang: Genta Singgalanga Press.

[15] Saleh, S. (2017). Peran Lembaga Pendidikan Dalam Membentuk Karakter Bangsa. Prosiding Seminar Nasional Himpunan Sarjana Pendidikan IlmuIImu Sosial Indonesia, 101. Himpunan Sarjana Pendidikan Ilmu-ilmu Sosial Indonesia. 
[16] Salim, \& Syahrum. (2012). Metodologi Penelitian Kualitatif. Bandung: Citapustaka Media.

[17] Sugiyono. (2010). Metode Penelitian Pendidikan (pendekatan Kualitatif, Kuantitatif dan R\&D). Bandung: Alfabeta.

[18] Suradarma, I. B. (2018). Revitalisasi Nilai-nilai Moral Keagamaan di Era Globalisasi Melalui Pendidikan Agama. Jurnal DHARMASMRTI, 9(2), 50.

[19] Susanti, M. (2014). Study Baliak Nagari Baliak ka Surau As Local Wisdom In Kenagarian Koto Tangah Tilatsng Kamang District District West Sumatra Agam. Jurnal Online Mahasiswa Faklutas IImu Sosial Dan IImu Politik Universitas Riau, 1(1), 2.

[20] Syafe'i, I. (2017). Pondok Pesantren Lambaga Pendidikan Pembentukan Karakter. Al-Tazkiyyah: Jurnal Pendidikan Islam, 8(1), 63.

[21] Widoyoko, E. P. (2012). Teknik Penyusunan Instrumen Penelitian. Yogyakarta: Pustaka Pelajar.

[22] Yusutria. (2018). Analisis Mutu Lembaga Pendidikan Berdasarkan Fungsi Manajemen di Pondok Pesantren Thawaliab Padang Sumatera Barat. Ta'dib: Jurnal Pendidikan Islam, Л(2), 84.

[23] Zubaedi. (2011). Desain Pendidikan Karakter: Konsepsi dan Aplikasinya dalam Lembaga Pendidikan. Jakarta: Kencana. 